\title{
A romantização da maternidade e a culpabilização da mulher.
}

\author{
The romanticization of motherhood and the blaming of women
}

Ruane Cristine Bernardes César ${ }^{\dagger *}$, Amanda Freitas Loures ${ }^{\ddagger}$, Bárbara Batista Silveira Andrade ${ }^{\S}$

Como citar esse artigo. César,

R.C.B; Loures, A.F.; Andrade, B.B.S.

A romantização da maternidade e a

culpabilização da mulher. Revista

Mosaico 2019 Jul./Dez.; $10 \quad$ (2):

SUPLEMENTO 68-75

\author{
Resumo \\ Este artigo busca apresentar uma revisão narrativa da literatura acerca da romantização da maternidade e seus reflexos num \\ processo de culpabilização da mulher, através do qual a mesma passa a apresentar sentimentos ambíguos com relação à \\ maternidade, uma vez que, por diversos motivos, sente-se dividida entre sua profissão, suas escolhas pessoais e a necessidade \\ de oferecer cuidados integrais a seu filho, uma vez que este discurso é reforçado pela sociedade e pela mídia. Por outro lado, \\ a mulher-mãe passa por um luto ao ter que abrir mão de parte da sua vida para cuidar da criança, que ocupará parte de seu \\ espaço.Destaca-se, ainda, a naturalização da maternidade e a construção de uma representação do "instinto materno" que recai \\ fortemente sobre as mulheres que não desejam ser mães. \\ Palavras-chave: Maternidade, Romantização, Culpabilização.
}

\begin{abstract}
This article aims to present a narrative review of the literature about the romanticization of motherhood and its reflexes in a process of blaming women, through which she begins to present ambiguous feelings about motherhood, since, for various reasons, she feels It is divided between your profession, your personal choices and the need to provide comprehensive care for your child, as this discourse is reinforced by society and the media. On the other hand, the mother-woman goes through a mourning when she has to give up part of her life to take care of the child, who will occupy part of her space. of the "maternal instinct" that falls heavily on women who do not wish to be mothers.

Keywords: Maternity, Romanticization, Blaming.
\end{abstract}

\section{Introdução}

A maternidade é uma questão sobre a qual todas as mulheres, em algum momento de suas vidas, irão refletir. Tanto as mulheres que desejam ser mães como aquelas que não desejam, sofrem algum tipo de cobrança social acerca da maternidade. Por motivos diversos (culturais, sociais e históricos), ser mãe tornou-se algo compulsório, de modo que muitas mulheres sentem-se culpadas por não desejarem um filho ou por, mesmo desejando, terem dúvidas e medos com relação aserem mães.

Segundo Caporal et al. (2017), há uma romantização da maternidade enquanto realização da mulher, que desconsidera suas subjetividades e as opressões por elas vivenciadas, para que se dediquem exclusivamente ao(s) filho(s), algo que não é igualmente cobrado dos homens/pais. Do mesmo modo, mulheres que optam por não terem filhos sofrem coma pressão da maternidade compulsória, encarada como destino natural de todas as mulheres.

Do mesmo modo, Badinter (1980), aponta que o amor maternal não é da essência da mulher, de modo que seu interesse e dedicação pelo filho(a) podem ocorrer, ou não. Ainda, os papeis sociais de mãe e de pais tampouco são naturais, estando subordinados a exigências e valores dominantes de cada sociedade.

Neste contexto, este artigo tem por objetivo apresentar uma revisão narrativa de literatura, com base em autores e autoras do campo da psicologia, dos feminismos e do debate sobre gênero, inseridos nas teorias pós-estruturalistas, através do qual possa ser demonstrada a romantização da maternidade como origem de uma culpabilização da mulher mãe e não-mãe, apontando para o fato de que as mulheres desenvolvem um sentimento de culpa, proveniente das

Afiliação dos autores: †Graduanda em Psicologia,Curso de Psicologia, Universidade de Vassouras, Vassouras/RJ, Brasil

*Graduanda em Psicologia, Curso de Psicologia, Universidade de Vassouras, Vassouras/RJ, Brasil

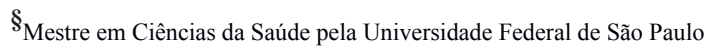

* Email de correspondencia: ruanebernardes12@gmail.com 
pressões sociais impostas pela sociedade machista e patriarcal, que valoriza a fertilidade, como se essa fosse uma dádiva de Deus e deprecia a infertilidade tida como um castigo, ou o não desejo de ter filhos, como algo não natural e que coloca as mulheres em um não-lugar, negando sua feminilidade e dando a elas um status de "menos mulheres".

\section{O ser mulher e o movimento feminista}

Segundo Oliveira (2007), a representação social da maternidade vem sendo modificada, adaptandose a cada época e cada sociedade em que encontra-se inserida. Do mesmo modo, as representações da mulher também foram mudando ao longo dos tempos, mas nunca deixaram de estar submetidas ao olhar masculino hegemônico, que tende a compreendê-las sempre como inferiores.

Araújo (2004) relata que, no período colonial e posteriormente no Império, a mulher era ensinada a ser uma boa mãe e esposa, servir ao marido e a casa e nunca desejar ocupar o espaço público. Além disso, sua educação era diferente daquela destinada aos meninos, limitada ao mínimo. Apenas as que tivessem por destino convento, teriam acesso a mais leituras; as demais aprendiam o que interessasse ao funcionamento de seu futuro lar: ler, escrever, contar, coser e bordar" (ARAÚJO, 2004 p. 41). Para além disso, a maternidade era também representada e regulada pelo olhar masculino e da igreja:

[...] com prazer ou sem prazer, com paixão ou sem paixão, a menina tornava-se mãe, e mãe honrada, criada na casa dos pais, casada na igreja. Na visão da sociedade misógina, a maternidade teria de ser o ápice da vida da mulher. Doravante, ela se afastava de Eva e aproximava-se de Maria, a mulher que pariu virgem o salvador do mundo. A Igreja não se fazia de rogada e estimulava tal associação (...). Porém, a mulher não podia exercer sua maternidade em paz. Os médicos homens logo entravam em cena para diminuir o brilho do milagre e do mistério da fecundidade e para dizer à mulher que ela continuaria dependente do saber, e do poder, masculino (ARAÚJO, 2004, p. 43).

Segundo Bittencourt (2013), o modelo de divisão social em que a mulher ficava enclausurada no lar e o homem seguia a vida pública, era interessantepara aqueles que possuíam capital, que deixariam uma herança, pois assim a hierarquia familiar seria mantida.

Apenas no século XIX começa a participação feminina no espaço público, porém aquelas que trabalhavam ainda não eram vistas com bons olhos pela sociedade. Segundo Oliveira (2007), com o início da Segunda Guerra Mundial (1939), o mundo não tem outra saída a não ser "deixar" que as mulheres assumam os postos de trabalho que antes pertenciam aos homens que foram para a guerra; o que representou um salto inicial rumo às conquistas sociais femininas.Com o fim da guerra, porém, a mulher é obrigada a voltar para o lugar social que lhe competia: o lar. Ocorre que nem todas as mulheres aceitaram essa posição de volta, o que deu início apequenos movimentos de resistência feminina e se intensificou a partir dos anos de 1960, quando o movimento feminista ganha força e passa a questionar a divisão social e os papeis de gênero.

O movimento feminista ganha força e projeção, principalmente a partir dos escritos de Simone de Beauvoir, em sua obra "O segundo Sexo", de 1949, por possibilitar através de seu discurso, uma ruptura na história da mulher do século XX. O conteúdo do livro, à época, pareceu despertar nas mulheres o desejo por emancipação, conforme aponta Oliveira (2007).

No Brasil, segundo Mello (2017), as primeiras manifestações feministas tiveram como personagensmulheres da periferia de São Paulo, quese articulavam através de abaixo-assinados e reuniões em busca dediscutir os problemas dos bairros pobres e leválos às autoridades competentes. Tais grupos abordaram, ainda, temas como homossexualidade, aborto e sexualidade, considerados polêmicos na década de 1980 e na década de 1990, as feministas se debruçaram sobre os estudos de gênero e na busca por igualdade no mercado de trabalho, nos direitos sexuais e reprodutivos, e na divisão de tarefas, por exemplo.

Atualmente, a internet abriu espaço para que as ideias feministas circulem mais amplamente e o debate chegue à grande maioria das mulheres (MELLO, 2017). Desse modo, ampliaram-se as reflexões acerca do "ser mulher", do patriarcado e do machismo, do feminicídio e da maternidade compulsória.

\section{A maternidade compulsória}

Segundo Scavone (2001), um dos conceitos chave trazidos por Simone de Beauvoir foi o questionamento da maternidade como determinismo biológico reservado às mulheres como um destino imutável. O movimento feminista, a partir das leituras de Beauvoir, passou a pensar a maternidade como construção social e instrumento de dominação do sexo masculino sobre o feminino, de modo que a maternidade servia paradelimitar o lugar das mulheres na sociedade: em casa, cuidando dos filhos. A partir de então, a luta política pela interrupção da gravidez passou a estar na pauta do Movimento Feminista.

A partir dos anos 90, com o olhar do feminismo voltado às relações de gênero, a maternidade começou a ser novamente problematizada, considerando, dessa vez, suas múltiplas facetas e subjetividades relacionadas ao ser mulher-mãe. Desse modo, começa-se a pensar a romantização da maternidade, como símbolo ideal de realização da mulher; ou ainda como representação da 
opressão das mesmas, ou como símbolo de poder. Ou seja, a maternidade passa a ser vista através de diferentes interpretações de um símbolo, mas principalmente, ela é entendida como um processo histórico, cultural e político, ligada diretamente às relações de poder e dominação de um sexo sobre o outro (SCAVONE, 2001).

Apesar de todos estes movimentos, persistem até hoje, discursos que abordam a maternidade como destino e realização da mulher, demodo que ela deve aceitar que "todas nascemos para sermos mães", e que a maternagem é seu papel exclusivo. É este ocontexto que abre espaço para as reflexões que faremos a seguir.

\section{A romantização da maternidade e a culpabilização da mulher.}

Segundo Oliveira (2007), inúmeros discursos sociais foram constituindo e reforçando o papel da mulher como mãe ao longo da história feminina na sociedade moderna. $\mathrm{O}$ discurso literário, por exemplo, sempre trouxe uma imagem romantizada da mulher-mãe como feliz e realizada, de modo que qualquer mulher que se negasse a desejar um filho estaria fugindo de sua natureza, questionando aquilo que foi discursivamente instituído como sua essência.

O discurso da mídia é outro viés através do qual institui-se a maternidade como um processo unicamente feminino e compulsório. Segundo Marcello (2005, p. 86), "É válido apontar que, de um modo sutil, se renovam estratégias semelhantes àquelas usadas por enunciados médicos - oriundos do século XVII - que evidenciavam a vocação "natural" da mulher à maternidade".

A autora citada aponta para a existência de discursos que buscam convencer a mãe de que seus filhos precisam de sua atenção em tempo integral, fazendo com que as mulheres passem a acreditar que devem deixar seus empregos para se dedicar aos cuidados maternos. Além disso, conforme aponta a autora, a mídia apresenta um discurso que reitera a assimetria entre as funções paternas e maternas como algo natural, de modo que as mães que deixam seus filhos sob responsabilidade paterna são vistas como desleixadas ou irresponsáveis.

Ao mesmo tempo em que alguns discursos midiáticos impulsionam a mulher a ser "somente mãe", no contexto contemporâneo, em que a mulher está inserida no mercado de trabalho e ainda, na maioria das vezes, é responsável pelas tarefas domésticas, há um contradiscurso, segundo o quala mulher deve ser boa em tudo, sem abrir mão de nada, o que faz com que a mulher desenvolva sentimentos ambíguos com relação à maternidade e sinta-se duplamente culpada: quando não deixa o emprego e os afazeres para dedicarse exclusivamente ao filho, ou quando abandona sua carreira e seus projetos profissionais para ficar com a criança.

Tomando mais uma vez o discurso midiático como impulsionador da culpabilização materna, Halasi (2018), discute alguns discursos de atrizes famosas em redes sociais que são carregados de simbologia ao relacionarem o parto e a maternidade como processos naturais, fazendo com que muitas mulheres que não tiveram as mesmas experiências, sintam-se aquém do ideal, incapazes; ou ainda, com que aquelas que não desejam se doar integralmente à maternidade sejam vistas com estranhamento. A autora afirma que "[...] a tentativa de veicular este modelo midiático de mãe retira toda a vivência subjetiva e inconsciente, tanto da mãe quanto do filho, uma vez que não são os eventos reais que marcam, mas as representações que ficam delas".

No mesmo sentido, Grisci (1995, p.14/15), destaca:

Há, também, uma intensa legitimação do acontecer da maternidade, via meios de comunicação de massa alicerçada na naturalização, eternalização e normatização [...]. Na infância tendem a se estruturar bases sólidas de construção e diferenciação de gênero, a serem reforçadas no decorrer da vida. A partir da infância, nota-se que as intervenções mostram-se mais sutis, mas nem por isso menos acirradas, em nível de cobranças quanto à execução desse papel.

Além das representações simbólicas advindas do parto e da maternidade como "essência", inculcadas no imaginário feminino desde a infância,a mulhermãe precisa lidar com sua vida profissional, as tarefas domésticas e no caso das mulheres casadas ou em um relacionamento, de sua vida afetiva, tudo isso em meio a um luto. Sim, pode-se afirmar, segundo Halasi (2018), que a maternidade inclui um luto de si; uma constante demanda por abrir mão de sua subjetividade para cuidar de outra pessoa.

A autora toma os ensinamentos de Freud (2010 apud Halasi, 2018), para afirmar que as gestantes passam por um luto, pois perdem um pouco de si ao cederem lugar ao bebê, que ocupará um pouco de seu espaço. Este luto precisa ser resolvido em um curto período de tempo, em que coabitam, muitas vezes as sensações de perda e ganho, o vazio e a ausência de si e a necessidade de estar "pronta", perfeita e ser uma boa mãe. Neste mesmo sentido, Badinter (2011) questiona se esta representação do "instinto materno" não é justamente a causa da culpa sentida pela mulher e da recusa da maternidade.

Segundo Halasi (2018, p. 63), as questões acima elencadas fazem com que, atualmente, as mulheres vivam a "maternidade da culpa". Dividida entre o lar e o trabalho, os filhos e a carreira, e a necessidade de "dar conta de tudo", a mulher acaba ocupando o nãolugar, o limbo social e emocional. Segundo a autora, "a maternidade da culpa é vivida em cada etapa da decisão, seja enquanto uma escolha, enquanto uma questão 
financeira, enquanto um parto, uma amamentação, uma doação possível, enfim, enquanto espaços que podem ou não ser abertos".

Grisci (1995, p.16 ), complementa
este raciocínio, afirmar que:
Mesmo para as mulheres que exercem atividades as
mais diferenciadas possíveis, a maternidade ainda se
caracteriza como a atividade mais sublime de suas vidas.
E, algumas vezes, não só é referida pela linguagem do
trabalho, "mãe de tempo integral" e "dedicação exclusiva",
como é vivenciada como sendo o próprio trabalho. A
mulher-mãe incorpora duas dimensões, a mãe real e
a mãe ideal, sendo o choque entre ambas inevitável.

Além da maternidade da culpa, chamamos atenção para um processo que recai também, fortemente, sobre as mulheres que não desejam ser mães. A partir da romantização da maternidade como realização última da mulher, a sociedade olha com estranhamento para as mulheres que não desejam ter um filho, como se abrir mão na maternidade, fosse abrir mão, também, de uma "essência feminina", tornando-se, por isso, menos mulher.

\section{A Romantização da maternidade e o olhar de estranhamento sob as mulheres que não desejam ser mães}

De acordo com Orsolin (2002), algumas modificações na sociedadepassaram a pesar sobre a decisão da mulher em ter filhos, entre elas, o surgimento da pílula anticoncepcional, a entrada da mulher no mercado de trabalho e a conquista da independência financeira, que deram origem a novas formas de subjetividade do ser mulher, fazendo com que a maternidade pudesse ser adiada ou recusada.

É importante deixar claro, porém, que o processo acima explanado não se deu de forma acrítica ou sem relações de poder e resistência por parte da sociedade. Ainda atualmente, segundo Scavone (2001), a sociedade compreende a maternidade como parte da essência e da identidade da mulher. Devido a isso, muitas mulheres optam arbitrariamente pela maternidade, sem fazerem maiores reflexões acerca deste processo, uma vez que foram ensinadas desde cedo que esse seria o caminho natural de todas as mulheres (ORSOLIN, 2002).

Conforme apontam Rios e Gomes (2009), ao não optar pela maternidade, a mulher passa a ser encarada pela sociedade com abjeção, pois compreende-se sua decisão como expressão de uma anormalidade, uma vez que não responde às expectativas sociais em relação ao papel social da mulher. Assim, as mulheres que abdicam da maternidade são vistas como egoístas, estranhas, doentes. Pessoas que não querem cumprir um "papel divino" que lhes foi dado. Conforme indicam Patias e
Buaes (2012, p.302):

As representações dos filhos como destino natural de toda mulherproduziuaperspectivadequeamaternidadeéocaminho daplenitude erealização da feminilidade. Trilhar esse caminho implica ter uma vida de renúncia e sacrifícios prazerosos indispensáveis à constituição da identidade feminina.

Por fim, relatamos a urgência de que a sociedade discuta a maternidade no sentido de desmistificá-la; demonstrando que os processos de subjetivação da mulher não são homogêneos e unos. Cada mulher é diferente da outra e merece ser compreendida como tal.

Além disso, é necessário que homens participem desta desconstrução, assumam seus papéis mediante a paternidade e quebrem paradigmas que colocam a mulher como única responsável pelos filhos, e que fazem com que a maternidade seja vista como algo natural e, além disso, compulsório.

\section{Considerações finais}

São inúmeras as pressões sofridas pelas mulheres ao longo dos anos, uma vez que estão inseridas em uma sociedade patriarcal e machista. Algumas concepções acerca do ser mulher vem sendo produzidas e reproduzidas pela sociedade, no sentido de instituir o processo de subjetivação feminino como uma essência, algo natural que existisse em todas as mulheres e que não pode ser negado. Entre tais essencialismos, está a maternidade.

Há um regime de verdade difundido na sociedade, segundo o qual a maternagem é vista como destino da mulher; romantizada; como um feito que elevaria a feminilidade e transformar-se-ia na maior realização da vida das mulheres.

O movimento feminista buscou problematizar esse discurso e pensar a maternidade como construção social, histórica e cultural, de modo que a maternidade fosse vista como decisão e construção social, podendo a mulher optar por ter filhos, e construir uma identidade materna, não existente a priori; ou não ter filhos, por compreender que este não é um destino fatídico e não reconhecer em si o desejo de ser mãe.

Nos dois casos citados, a mulher passa por um processo de culpabilização por parte da sociedade e de si mesma. Ao optar por ser mãe, sente-se culpada, ao continuar a trabalhar e também ao abandonar sua carreira, uma vez que há discursos contraditórios na sociedade que, ao mesmo tempo que esperam que a mulher dê conta de todas as suas tarefas, colocam sobre ela a responsabilidade de ser "mãe em tempo integral". Desse modo, a mulher desenvolve sentimentos ambíguos com relação à maternidade, além de viver um luto com a chegada do filho, conforme já explicitado neste artigo.

Por outro lado, a mulher que opta por não ter 
filhos, carrega o estigma social do egoísmo, da abjeção e do estranhamento, uma vez que nega aquilo que segundo o senso comum, lhe seria natural.

Nesse contexto, é necessário repensarmos a maternidade enquanto construção sócio-histórica e cultural, potencializando o enfrentamento de um discurso que traz a mesma como um dom natural às mulheres. Dessa forma, toda a de experiências é respeitada e valorizada, sendo um direito da mulher viver a pluralidade conforme seu próprio desejo.

Se compreendermos, como dito anteriormente, que cada mulher constrói, sócio e culturalmente suas representações acerca da maternidade, passaremos a compreender, também, a não naturalidade desse processo e o fato de que nem todas as mulheres desejam ser mães, respeitando as escolhas das mulheres e contribuindo, assim, para um olhar mais amplo e compreensivo sobre a maternidade. Há, ainda, um caminho a ser trilhado. Esperamos, com este trabalho, ter contribuído um pouco para que este caminho não seja tão longo.

\section{Referências}

ARAÚJO, E. A arte da sedução:Sexualidade feminina na colônia. In: PRIORE, Mary Del (org); Bassanezi, Carla (coord. de textos). História das mulheres no Brasil. 7. ed. - São Paulo : Contexto, 2004.

BADINTER, E. O amor incerto. Lisboa: Relógio d'Água. 1980.

BADINTER, E.O conflito: a mulher e a mãe. Rio de Janeiro: Record, 2011.

BITTENCOURT, D. M. M. de. Casa, alcova e mulher. Santa Cruz do Sul: EDUNISC, 2013

CAPORAL, B. R et.al. Romantização da maternidade: reflexões sobre gênero. XXII Seminário Institucional de Ensino Pesquisa e Extensão [Anais],2017.Disponível em:https://home.unicruz.edu.br/seminario/anais/ anais.pdf Acesso em 16 set. 2019.

GRISCI, C. L. I. Mulher - mãe. Psicol. cienc. prof., Brasília, v. 15, n. 1-3, p. 12-17, 1995. Disponível em: <http://www.scielo.br/scielo.php?script=sci arttext\&pid=S1414-98931995000100003\&lng=en\&nrm=iso $>$. Acesso em 17 Set. 2019.

HALASI, F. S.A mulher brasileira contemporânea e a maternidade da culpa. PONTIFICIA UNIVERSIDADE CATÓLICA DE SÃO PAULO, Mestrado em Psicologia Clínica, 2018.

MARCELlO, F. A. de. Dispositivo da maternidade: mídia e a produção pedagógica de sujeitos, práticas e normas. Educar, Curitiba, n. 26, p. 8198, 2005. Editora UFPR. Disponível em: http://www.scielo.br/pdf/er/n26/ n26a07.pdf Acesso em 16 set 2019.

MELLO, C.B. de. Documentário: maternidade compulsória:Uma revisão do que significa a maternidade sob o ponto de vista do feminismo. 2017. [31] p. Trabalho de conclusão de curso (bacharelado - Comunicação SocialJornalismo) - Universidade Estadual Paulista Júlio de Mesquita Filho, Faculdade de Arquitetura, Artes e Comunicação, 2017. Disponível em: $<$ http://hdl.handle.net/11449/155718>. Acesso em 16 set 2019

OLIVEIRA, P. B. de. A mulher atual e a representação da maternidade. Universidade Católica De Pernambuco Pró-Reitoria de Ensino, Pesquisa e Extensão - Mestrado em Psicologia Clínica. Recife, 2007. Disponível em: http://livros01.livrosgratis.com.br/cp131225.pdf Acesso em 16 set. 2019.

ORSOLIN, R. Nem toda mulher quer ser mãe: novas configurações do feminino. Em Cenci, C. M. B, Piva, M. \& Ferreira, V. T. R. Relações Familiares: uma reflexão contemporânea. Passo Fundo: UPF Editora,2002.

PATIAS, N. D.; BUAES, C. S. "Tem que ser uma escolha da mulher"!representações de maternidade em mulheres não-mães por opção.
Psicol. Soc., Belo Horizonte, v. 24, n. 2, p. 300-306, 2012. Disponível em: $\quad<$ http://www.scielo.br/scielo.php?script=sci arttext\&pid=S0102$71822012000200007 \& \operatorname{lng}=\mathrm{en} \& \mathrm{nrm}=$ iso $>$. Acesso em 17 Set. 2019.

RIOS, M. G.;GOMES, I. C. Casamento contemporâneo: revisão de literatura acerca da opção por não ter filhos. Estudos de Psicologia, v. 26, n. 2, p. 215 $225,2009$.

SCAVONE, Lucila. A maternidade e o feminismo: diálogo com as ciências sociais. Cadernos Pagu (16), Campinas-SP, Núcleo de Estudos de GêneroPagu/Unicamp, 2001, pp.137-150.Disponível em: http://www.scielo.br/pdf/ cpa/n16/n16a08.pdf Acesso em 16 set 2019. 


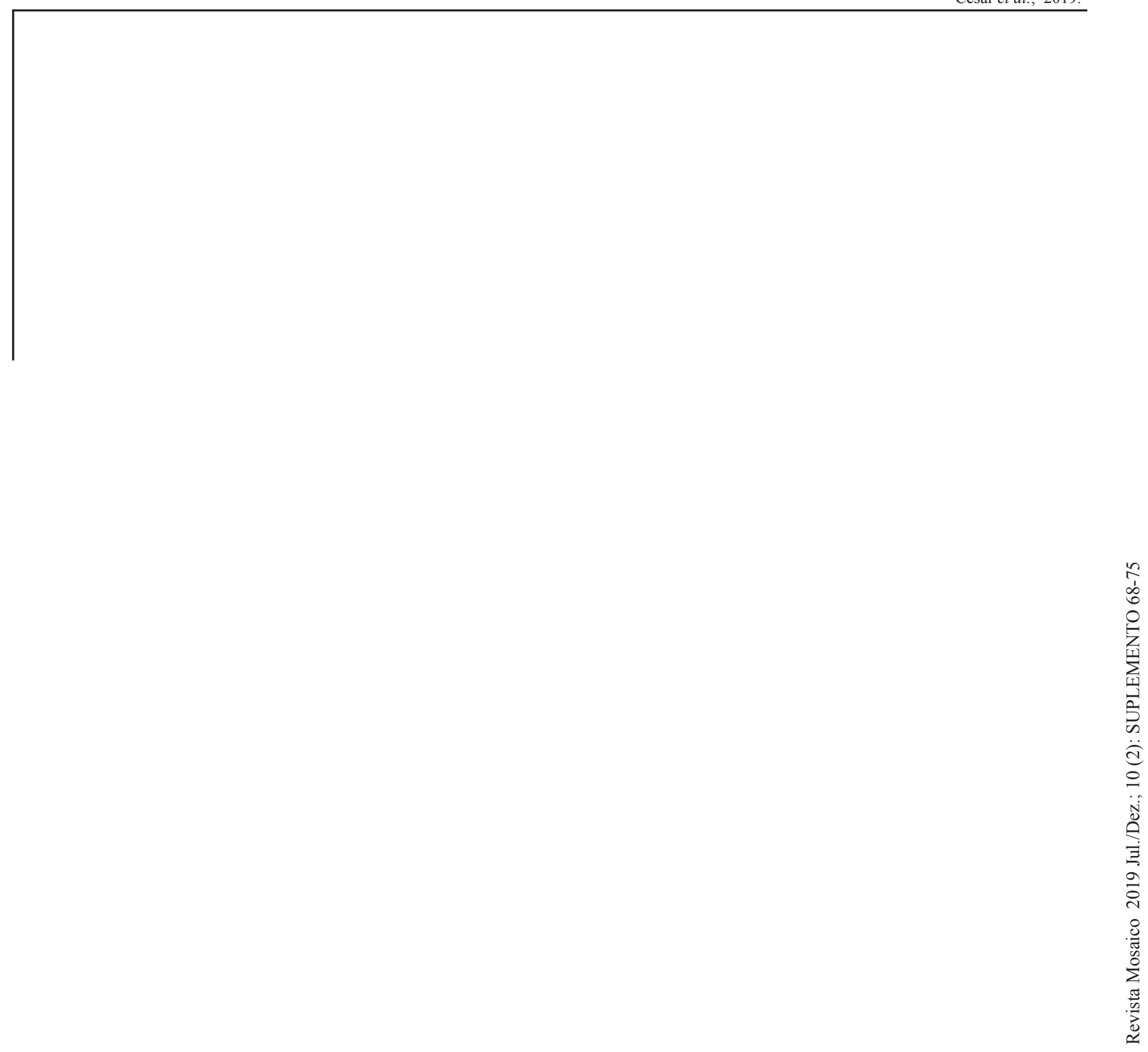




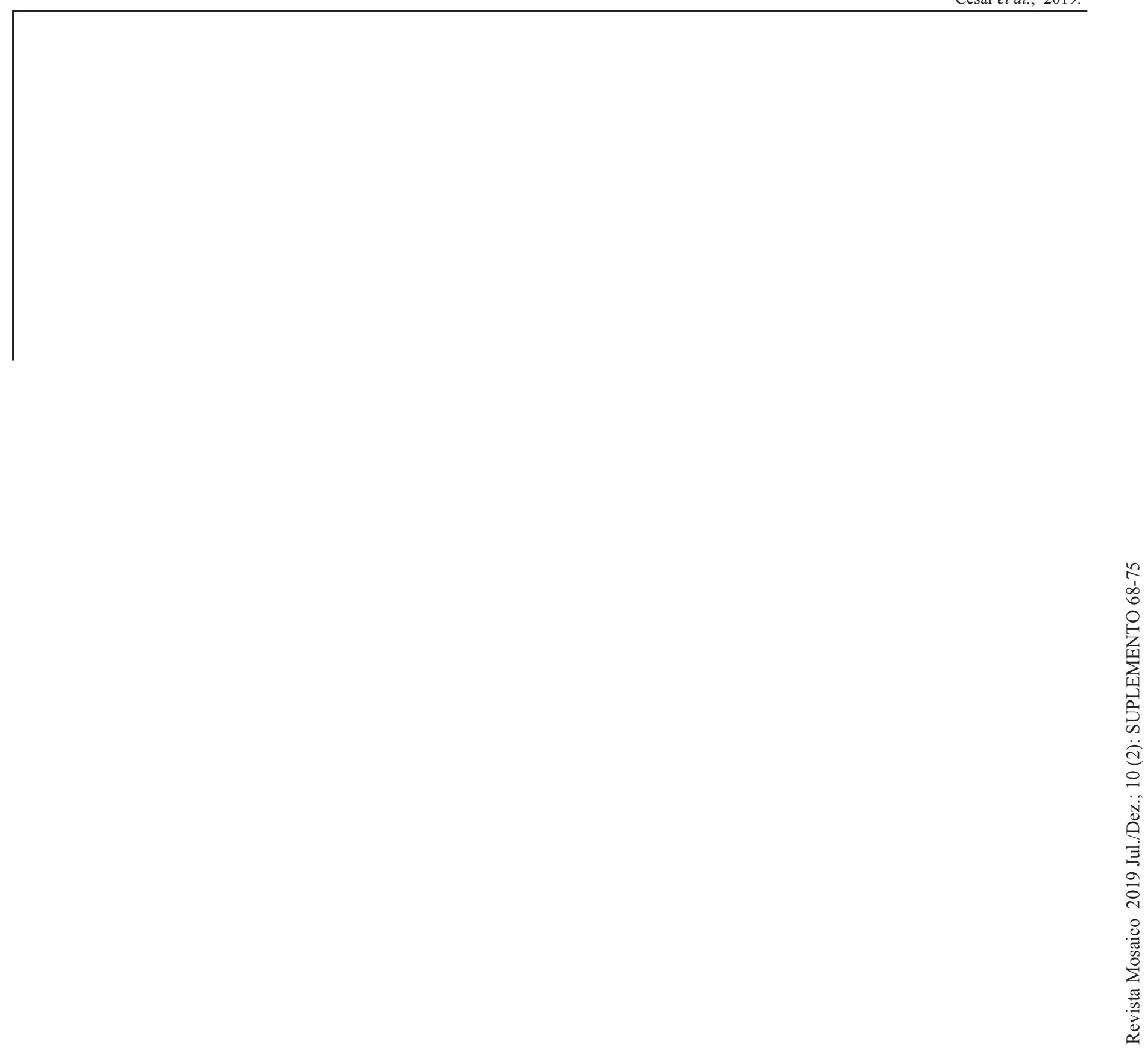

